\title{
Horizontal Nail Ridging
}

National Cancer Institute

\section{Source}

National Cancer Institute. Horizontal Nail Ridging. NCI Thesaurus. Code C112814.

Linear transverse/horizontal groove of one or more nail plates that migrate distally from the proximal nail fold with nail growth, usually secondary to illness, trauma or malnutrition. 